University of Nebraska - Lincoln

DigitalCommons@University of Nebraska - Lincoln

Faculty Publications in Food Science and Technology

2019

Histone acetylation increases in response to ferulic, gallic, and sinapic acids acting synergistically in vitro to inhibit Candida albicans yeast-to-hyphae transition

Cristiane R. S. Câmara

Qin-Yin Shi

Matthew Pedersen

Richard Zbasnik

Kenneth Nickerson

See next page for additional authors

Follow this and additional works at: https://digitalcommons.unl.edu/foodsciefacpub

Part of the Food Science Commons, and the Microbiology Commons

This Article is brought to you for free and open access by the Food Science and Technology Department at DigitalCommons@University of Nebraska - Lincoln. It has been accepted for inclusion in Faculty Publications in Food Science and Technology by an authorized administrator of DigitalCommons@University of Nebraska Lincoln. 
Authors

Cristiane R. S. Câmara, Qin-Yin Shi, Matthew Pedersen, Richard Zbasnik, Kenneth Nickerson, and Vicki Schlegel 


\title{
Histone acetylation increases in response to ferulic, gallic, and sinapic acids acting synergistically in vitro to inhibit Candida albicans yeast-to-hyphae transition
}

\author{
Cristiane Rodrigues S. Câmara, ${ }^{1}$ Qinyin Shi, ${ }^{1}$ \\ Matthew Pedersen, ${ }^{2}$ Richard Zbasnik, ${ }^{1}$ \\ Kenneth W. Nickerson, ${ }^{3}$ and Vicki Schlegel ${ }^{1}$ \\ 1 Department of Food Science and Technology, University of \\ Nebraska-Lincoln, Lincoln, Nebraska, USA \\ 2 Department of Agronomy and Horticulture, University of Nebraska- \\ Lincoln, Lincoln, Nebraska, USA \\ 3 School of Biological Sciences, University of Nebraska-Lincoln, \\ Lincoln, Nebraska, USA \\ Corresponding author - Vicki Schlegel, Department of Food Science and \\ Technology, University of Nebraska-Lincoln, 1901 N 21 St-Food Innovation \\ Campus, Lincoln NE 68588, USA. Email: vschlegel3@unl.edu \\ ORCID — C.R.S. Câmara http://orcid.org/0000-0003-0148-8186
}

\begin{abstract}
Novel treatments are needed to prevent candidiasis/candidemia infection due to the emergence of Candida species resistant to current antifungals. Considering the yeast-to-hyphae switch is a critical factor to Candida albicans virulence, phenols common in plant sources have been reported to demonstrating their ability to prevent dimorphism. Therefore, phenols present in many agricultural waste stress (ferulic (FA) and gallic (GA) acid) were initially screened in isolation for their yeast-tohyphae inhibitory properties at times 3, 6, and $24 \mathrm{hr}$. Both FA and GA inhibited 50\% of hyphae formation inhibitory concentration $\left(\mathrm{IC}_{50}\right)$ but at a concentration of 8.0 \pm 0.09 and $90.6 \pm 1.05 \mathrm{mM}$, respectively, at $24 \mathrm{hr}$. However, the inhibitory effect of
\end{abstract}

Published in Phytotherapy Research. 2019;33:319-326.

DOI: $10.1002 / p t r .6222$

Copyright ( $) 2018$ John Wiley \& Sons, Ltd. Used by permission.

Submitted 18 January 2018; revised 3 September 2018; accepted 28 September 2018 
FA increased by $1.9-2.6$ fold when combined with different GA concentrations. GA and FA values decreased even lower when sinapic acid (SA) was added as a third component. As evidenced by concave isobolograms and combination indexes less than 1, both GA:F A and GA:FA:SA combinations acted synergistically to inhibit $50 \%$ hyphae formation at $24 \mathrm{hr}$. Lastly, acetylation of histone H3 lysine 56 acetylation (H3K56) was higher in response to the triple phenolic cocktail (using the IC50 $24 \mathrm{hr}$ inhibitory concentration level) comparable with the nontreated samples, indicating that the phenols inhibited hyphal growth in part by targeting H3K56 acetylation.

Keywords - acetylation, Candida albicans, N-acetylglucosamine, phenols, synergism, yeast-to-hyphae transition

\section{Introduction}

Candida albicans inhabits the human gastrointestinal, oral, and vaginal mucosa as a dormant commensal member but can become an opportunistic pathogen when its environment is compromised. The pathogenicity of $C$. albicans has been linked to its ability to switch from a yeast-to-hyphae phenotype (Sudbery, Gow, \& Berman, 2004) as the latter filamentous form facilitates penetration of the epithelial tissue followed by colonization to other body organs (Phan, Myers, Fu, et al., 2007). Candida infections of the mucosal membranes (candidiasis) or the bloodstream (candidemia; Miceli, Díaz, \& Lee, 2011) have led to mortality rates of $30-40 \%$ in critically ill individuals (immunodeficiency syndrome, hematological malignancy) (Kullberg \& Arendrup, 2015). In fact, C. albicans has become the most common cause of nosocomial bloodstream infection in hospitalized patients (Magill, Edwards, Bamberg, et al., 2014).

However, anticandidal agents are critically limited, with only the azoles and polyenes providing the most effective protection (Sardi, Almeida, \& Mendes Giannini, 2011; Sudbery et al., 2004). With the increased use of these two types of antifungal agents, Candida species resistant to azoles and polyenes is also increasing (Lortholary et al., 2011; Zida, Bamba, Yacouba, Ouedraogo-Traore, \& Guiguemdé, 2017). For example, fluconazole resistant $C$. albicans has recently been declared a "serious threat" by the US Centers for Disease Control and Prevention (CDC, 2013).

Development of antifungals that act on virulence factor rather than killing the benign organism is gaining interest (Shareck \& Belhumeur, 2011). This treatment strategy is especially significant when a microbe is a natural member of the human microbiome, such as $C$. albicans, as 
killing the nonpathogenic members may result in colonialization of a more lethal organisms. Another complementary strategy for protecting against infectious organisms also garnering more attention is the use of a cocktail of antifungals that preferably act as synergists (Lewis $\&$ Kontoyiannis, 2001). Thus, the antifungal activity is expected to be greater than the individual contribution of each compound, and a potential benefit is the reduction of $C$. albicans resistance to these synergistic agents.

Plant based phenols have been shown to induce multiple health benefits, including protecting against human infectious diseases (Faria et al., 2011; Gallucci et al., 2014). These compounds are ubiquitously distributed in the plant kingdom and, as secondary metabolites, protect the plant against several environmental stressors (Manach, Scalbert, Morand, Rémésy, \& Jiménez, 2004). The potential antifungals have been primarily studied based on their ability to inhibit cellular growth (Faria et al., 2011; Guzman, 2014; Kanwal, Hussain, Latif Siddiqui, \& Javaid, 2010). Isolated phenols are also typically used for these purposes despite emerging evidence that show whole food systems or phenolic-rich extracts impart greater benefits than the sum of the individual components (synergism) (Junio, Sy-Cordero, Ettefagh, et al., 2011).

Yet, a critical lack of knowledge remains on the ability of phenolic synergists to prevent the $C$. albicans hyphae phenotypes, with notable exceptions (Canonico et al., 2014; Kazuko, Sato, \& Azuma, 2010; Saito, Tamura, Imai, Ishigami, \& Ochiai, 2013). However, the referenced research does not account for responsible components or confirm whether those agents acted synergistically by constructing isobolograms or calculating the combination index (CI) (Junio et al., 2011). Therefore, the objective of our work was to evaluate the ability of phenols to act in combination as inhibitory synergists against $C$. albicans virulence switch. For this study, gallic (GA), ferulic (FA), and sinapic acid (SA) were selected as they are present in a wide variety of plant sources or are abundant in coproducts of agricultural based processes making them readily accessible for further isolation (Gallucci et al., 2014), and also showed the most potent effects (IC > $50>50$ ) when used in isolation compared with several other phenolic acids and flavonoids when tested at various concentrations.

As modulation of histone $\mathrm{H} 3$ lysine 56 acetylation (H3K56ac) has shown to affect morphogenesis of $C$. albicans cells (Kaplan et al., 
2008), the response of $\mathrm{H} 3 \mathrm{~K} 56$ acetylation (ac) was also monitored to determine a possible mechanistic target in response to the final synergistically active phenol cocktail.

\section{Materials and methods}

\subsection{Yeast-to-hyphae transition assay}

Culture stocks of $C$. albicans strain SC5314 (ATCC 2430) were prepared as described by Hornby et al. (2001). The cells were stored at $4^{\circ} \mathrm{C}$ in 50 $\mathrm{mM}$ potassium phosphate buffer ( $\mathrm{pH} \mathrm{6.5)} \mathrm{until} \mathrm{use.} \mathrm{Yeast} \mathrm{cells} \mathrm{from}$ the stock cultures were induced to the hyphae form by inoculating 1.5 $\times 10^{7}$ cells per milliliter into $125 \mathrm{ml}$ Erlenmeyer shake flasks containing $25 \mathrm{ml}$ of $\mathrm{N}$-acetylglucosamine (GlcNAc) differentiation medium (DM2.8 ml of $0.1 \mathrm{M}$ imidazole buffer, $0.75 \mathrm{ml}$ of $0.1 \mathrm{M} \mathrm{MgSO}_{4^{\prime}} 0.65 \mathrm{ml}$ of $0.1 \mathrm{M} \mathrm{GlcNAc}$, and $20.8 \mathrm{ml}$ of nanopure water), $\mathrm{pH} \sim 6.5$ (Hornby et al., 2001). Flasks were incubated at $37^{\circ} \mathrm{C}$ for $24 \mathrm{hr}$ with constant aeration and agitation (250 rpm). Samples were collected at $0,3,6$, and $24 \mathrm{hr}$ of incubation for microscopic examination and histone extraction. Images of the cells were obtained by using an Olympus FV500 confocal laser scanning microscope (CLSM) with an Olympus IX81 inverted microscope with the UPlan SApo 60X/1.35 oil lens (Figure 1).

\subsection{Yeast-to-hyphae inhibition assay}

Caffeic acid was purchased from MP Biomedicals (Aurora, $\mathrm{OH}$ ) and quercetin from Alfa Aesar (Ward Hill, MA). All the other phenolic compounds (kaempferol, catechin, chlorogenic, and GA, FA, and SA) were obtained from Sigma-Aldrich (St. Louis, MO). Each phenol was prepared fresh in $0.0-2.2 \%$ dimethyl sulfoxide (DMSO) $(\mathrm{v} / \mathrm{v})$ to aid in solubility. DSMO levels did not exceed $2.2 \%$, because preliminary studies showed that higher levels contributed to hyphae inhibition. A given phenol was added at 2-5 different concentrations to DM. The highest phenol level used was based on its solubility capacity in 2.2\% DMSO. Cells from a fresh yeast stock were inoculated into the phenolic supplemented DM at $1.5 \times 10^{7}$ cells per milliliter and incubated at $37^{\circ} \mathrm{C}$ for $24 \mathrm{hr}$ with constant aeration and agitation (250 rpm). Medium containing only GlcNAc + DMSO served as the positive control. Aliquots 
of the media $(100 \mu \mathrm{l})$ were collected at $0,3,6$, and $24 \mathrm{hr}$ of incubation, and the cells were counted with a hemocytometer. Considering that DM does not allow cell proliferation, the number of hyphae cells was determined by subtracting the number of yeast cells at each time point (YC) from the number of initial cells (IYC) (at $0 \mathrm{hr}$ ). Percent of hyphae inhibition was calculated using the formula: (YC-YCC) /IYC) *100, where $\mathrm{YCC}=$ number of untransformed yeast cells in the positive controls at the corresponding sampling times point. Phenols that did not pass the screening process (percent inhibition greater than 25\%) were eliminated from further evaluation. For the phenols tested, GA, FA, and $\mathrm{SA}$ acids were able to inhibit $C$. albicans at $\mathrm{IC}_{25^{\prime}}$ a range of concentrations was selected for developing dose response curves (percent inhibition vs concentration millimolar) based upon their degree of efficacy determined from the screening trials. The two compounds that resulted in the highest percent inhibition after $24 \mathrm{hr}$ (GA and FA) were then combined. A base compound was then selected as the most efficacious agent, in this case FA. Thus, each of four FA solutions $(1,2,3$, and $4 \mathrm{mM}$ ) were combined with each of three GA concentrations (2.5, 7.5 , and $10 \mathrm{mM}$ ). The GA:FA combinations were monitored for their ability to prevent hyphal formation as described for the isolated components (Figure 3). After the two compound experiments were completed, phenols achieving minimally percent inhibition of $25 \%$ after 24 hr were combined with GA and FA, which in this case was only SA. Five concentrations of FA and $S A$ at $1: 1$ ratio $(1,2,3,4$, and $5 \mathrm{mM})$ were combined with three concentrations of GA $(2.5,7.5$, and $25 \mathrm{mM})$. (For clarification, $X$ millimolar FA:SA means that each phenolic acid was present at a final concentration of $X$ millimolar). Cells were inoculated at $1.5 \times 10^{7}$ cells per milliliter into the DM cocktail supplemented DM, analyzed as described above and were also used for histone extraction (untreated and the $24 \mathrm{hr}$ phenolics treated samples). Two-three replicates were completed for all the inhibition experiments and doseresponse curves were constructed from these results.

\subsection{Histone extraction and immunoblotting}

Histones were extracted immediately after finishing the inhibition studies as described by (Hasim, Tati, Madayiputhiya, Nandakumar, \& Nickerson, 2013). This procedure consisted of centrifuging the cells at $4-10^{\circ} \mathrm{C}$ until a pellet was formed and clear supernatant was apparent. 
After the pellets were washed twice in ice cold water, $\sim 0.5 \mathrm{~g}$ of the pellet was resuspended in $1 \mathrm{ml}$ of spheroplasting buffer, which consisted of $1 \mathrm{M}$ sorbitol, $25 \mathrm{mM}$ Tri-HCL, (pH 7.0) $100 \mathrm{mM}$ dithiothreitol, $10 \mathrm{mM}$ phenylmethanesulfonylfluoride, $25 \mathrm{mM}$ EDTA, and $0.01 \%$ $(v / v) \beta$-mercaptoethanol for $30 \mathrm{~min}$ at room temperature. The cells were then centrifuged again until the cell debris had pelleted that also contained a clear supernatant. The pellet was then subjected an addition time to $1 \mathrm{ml}$ of the spheroplasting buffer, but that also contained yeast cell-wall degrading enzymes ( $3.5 \mathrm{mg}$ zymolyse) for 3-4 $\mathrm{hr}$ with gentle shaking at $30^{\circ} \mathrm{C}$. The suspension was again centrifuged at $4-10^{\circ} \mathrm{C}$ until a pellet that now contained only the spheroplasts. The spheroplasts were submerged in in $1 \mathrm{ml}$ of histone extraction buffer (0.25 M sucrose, $60 \mathrm{mM} \mathrm{KCl}, 3 \mathrm{mM} \mathrm{MgCl}, 15 \mathrm{mM}$ Pipes $\mathrm{pH}$ 6.8, 0.8\% Triton $\mathrm{X}-100$, and protease inhibitor cocktail), overnight at $4^{\circ} \mathrm{C}$ with gentle rocking. The tubes were centrifuged at $9,000 \mathrm{~g}$ in a microfuge at $4^{\circ} \mathrm{C}$ for $20 \mathrm{~min}$, whereupon the pellets were resuspended in $1 \mathrm{ml}$ of $0.4 \mathrm{M} \mathrm{H} 2 \mathrm{SO} 4$, and centrifuged at $13,000 \mathrm{~g}$ for $5 \mathrm{~min}$. The supernatants were transferred to a new tube, and 12 volumes of cold. Acetone were added to precipitate the proteins overnight at $20^{\circ} \mathrm{C}$. The tubes were then centrifuged at $6,000 \mathrm{~g}$ for $15 \mathrm{~min}$, the pellets resuspended in $100 \mathrm{ml}$ of $4 \mathrm{M}$ urea.

Protein concentrations were determined using the Bradford assay (Bradford, 1976). Extracts of $20 \mu$ were separated on 17\% Tris- Glycine polyacrylamide gels, transferred onto polyvinylidene fluoride membranes and probed with rabbit anti-H3K56ac (1:2,000; Abcam) or rabbit anti-H3 (1:1,000; Abcam; da, Boyartchuk, Zhu, \& Kaufman, 2010). Antibody binding was detected using goat anti-Rabbit IgG conjugated to horseradish peroxidase (HRP; 1:20,000, Abcam) and was visualized by 3,3'-diaminobenzidine tetrahydrochloride (DAB) substrate (Thermo Scientific Pierce, Rockford, IL) until the desired staining intensity was obtained

\subsection{Statistical and synergism analysis}

A factorial design was applied to the individual compound inhibition experiments with replication, time, and compound as factors. After confirmation of insignificant replication effect, replicate data were pooled and the new factorial analyses included time and chemical using Fisher's least significant difference (LSD) at a significance 
level of $p<0.05$. Analysis of the combined compound experiments was completed similar to the isolated compounds, except that concentrations of each compound was used as a factor in the model. Treatment groupings for all data points were calculated using Fisher's LSD. Statistical Analysis System 9.3 was used to perform these analyses. One-way analysis of variance was calculated to compare different groups of Figure 5 using a Bonferroni post-hoc analysis. A significance level of $p<0.05$ was assumed for those statistical evaluations, which were computed with GraphPad Software. The combined phenols acting as synergists were analyzed by constructing isobolograms as previously described (Junio et al., 2011; Li, Wu, Wu, et al., 2014). Treatment concentrations that resulted in $50 \%$ inhibition of yeast-tohyphae $\left(\mathrm{IC}_{50}\right)$ after $24 \mathrm{hr}$ were plotted on isobolograms. The $I \mathrm{C}_{50}$ for each set of compounds was obtained by regression analysis fitted to the dose response curves (Figure 3 and 4). Synergism was substantiated by determining the $(\mathrm{Cl})$ calculated as follows: $\mathrm{Cl}=(\mathrm{c} 1 / \mathrm{C} \times 1)+(\mathrm{c} 2)$ $C_{x 2}$ ), where $C_{x} 1$ is the concentration of compound 1 required to inhibit $50 \%$ of hyphal form alone, and $c 1$ is the concentration of compound 1 required to produce the same effect in combination with $c 2$. Similarly, $C x 2$ is the concentration of compound 2 required to inhibit $50 \%$ of hyphal form alone, and $c 2$ is the concentration of compound 2 required to produce the same effect in combination with $c 1$. The $\mathrm{Cl}$ values were defined as follows: less than 1 , synergism; 1 , additive; and greater than 1, antagonism effect (Li et al., 2014).

\section{Results and discussion}

\subsection{Effects of isolated components on C. albicans yeast-to-hy- phae transition}

In this manuscript, isolated phenols were initially screened as potential inhibitors "to" the yeast-to-hyphae transition of C. albicans. Different concentrations of each phenol were added to the DM followed by inoculation of stationary yeast cells. Hyphae inhibition by each phenol at each of $4-5$ concentrations was determined at four time points ( 0 , 3,6 , and $24 \mathrm{hr}$ ). These time points were selected because cells at $0 \mathrm{hr}$ showed a typical yeast form, round to ovoid in shape and separated from each other (Figure 1). At $3 \mathrm{hr}$, greater than $95 \%$ of the cells were 
(a)

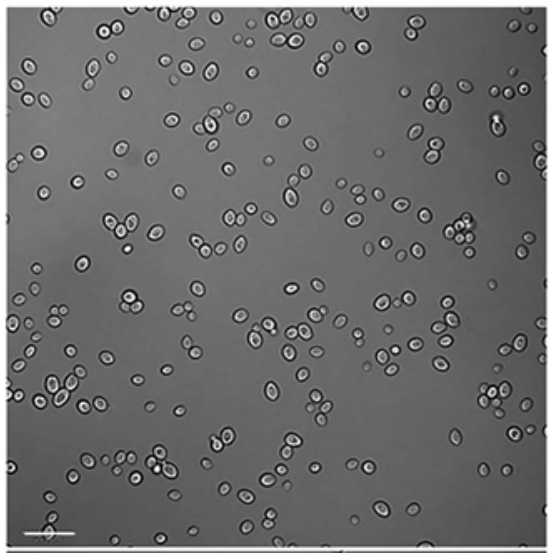

(c)

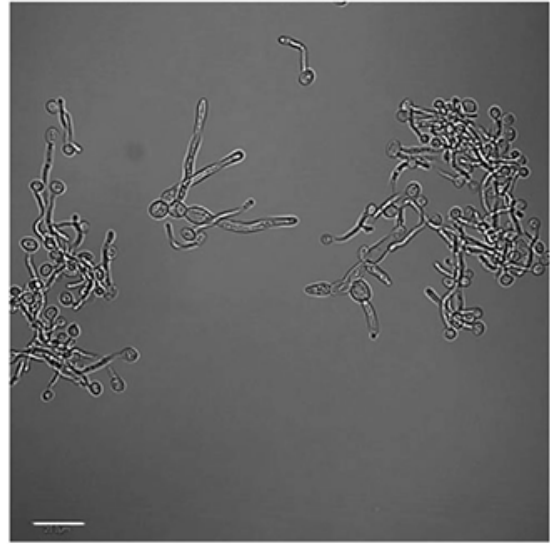

(b)

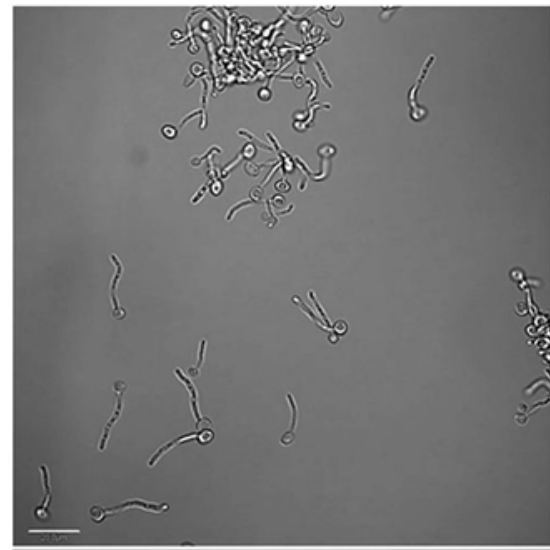

(d)

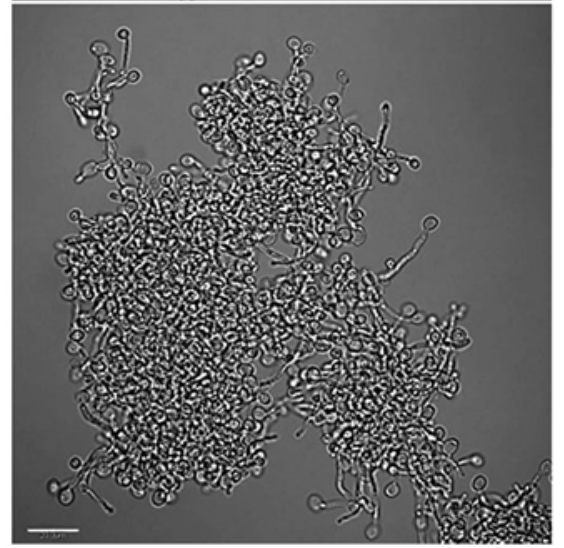

Figure 1. Morphology of Candida albicans cells during $24 \mathrm{hr}$ of yeast-to-hyphae transition induction. (a) $0 \mathrm{hr}$, control group, (b) $3 \mathrm{hr}$, (c) $6 \mathrm{hr}$, and (d) $24 \mathrm{hr}$ after incubation. Cells from $0 \mathrm{hr}$ time point were inoculated into $\mathrm{N}$-acetylglucosamine (GlcNAc) DM in order to induce germ tube formation. Scale bars represent $20 \mu \mathrm{m}$.

in the germ tube form, as expected, and partially grouped in small to medium clumps. Longer and wider filaments were apparent at $6 \mathrm{hr}$ compared with $3 \mathrm{hr}$, and the cells were mostly grouped in medium clumps. At $24 \mathrm{hr}$, all cells formed larger clumps and had transitioned mostly to hyphae (Figure 1). Another related study examined the effects of a flavonoid rich honey extract on the C. albicans phenotypic switch using similar incubation time (6 and $18 \mathrm{hr}$ ) used herein (Canonico et al., 2014).

Among the phenols tested for this experiment, kaempferol, caffeic acid, chlorogenic acid, quercetin, and catechin alone were not able to inhibit greater than $25 \%$ hyphae using concentrations soluble in the delivery system. These results do not support other published accounts where phenols were used for similar purposes, most notably, 
a catechin. Saito et al. (2013) showed that hyphae formation by C. albicans (NUD-202) was nearly inhibited at $2.8 \mathrm{mM}$ catechin using $10 \%$ fetal calf serum (FCS) as the inducing agent. For this study, $95 \%$ of $C$. albicans transitioned to hyphae within $3 \mathrm{hr}$ with $3.5 \mathrm{mM}$ catechin but GlcNAc was the inducer (data not shown). These experiments may differ due the use of different $C$. albicans strains and the inducing DM. Mosel, Dumitru, Hornby, Atkin, and Nickerson (2005) showed that different concentrations of farnesol $(1-250 \mu \mathrm{M})$ were able to reduce germ tube formation to $50 \%$ after $4 \mathrm{hr}$ when different inducing conditions and strains (SC5314 and A72) were used. Resveratrol (200-900 $\mu \mathrm{M}$ ) impaired the yeast-to-hyphae transition of C. albicans (SC5314) differently in terms of percent inhibition (treatment time of 60-300 min) and hyphal outgrowth under serum, $\mathrm{pH}$, and nutrient-induced conditions (Kazuko et al., 2010). The mode of action of an anticandidal in response to different DM or strains is most likely due to the flexibility of $C$. albicans to metabolize available nutrients in its various habitats within the host, and thereby, is able to activate a variety of signals specific to that niche (Brown \& Gow, 1999).

The inducing agent used in this study is an amino-sugar present in a number of eukaryotic cells, especially mucosal cells. As such, $C$. albicans encounters GIcNAc in many of its habitats resulting in the regulation of its genes involved in metabolism, morphogenesis, and virulence (Huang et al., 2010; Singh, Ghosh, \& Datta, 2001). GlcNAc activates $C$. albicans transition by regulating amino acid synthesis into a nitrogen limited condition (Brown \& Gow, 1999). Another study showed that at low ambient $\mathrm{pH}$, GlcNAc induced the hyphal cAMP dependent cascade pathway that caused filamentation using a mutant lacking genes to metabolize GlcNac (Singh et al., 2001). As evidenced by these seminal studies, GIcNAc has extensive regulatory control over C. albicans, thereby requiring higher levels of phenols to inhibit the switch. Studies are in progress to ascertain if lower phenols levels will be more effective with different inducing DM and C. albicans strains.

The most efficacious compound on hyphae inhibition was FA followed by GA (Figure 2) among the individual phenols tested. For GA, the percent inhibition increased in a dose-dependent manner at 3 and $24 \mathrm{hr}$ (Figure 2a). Interesting, only the highest GA concentration (80 $\mathrm{mM}$ ) was able to significantly inhibit hyphae formation after $6 \mathrm{hr}$ of treatment compared with the control $(p<0.05)$. Yet, the two highest concentrations (70 and $80 \mathrm{mM}$ ) induced the most effective inhibition 
(a)

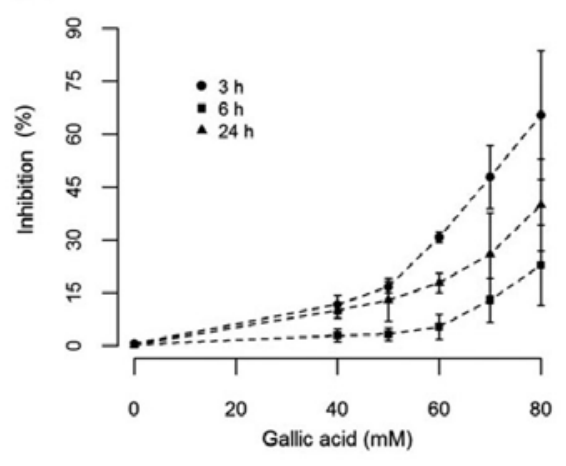

(b)

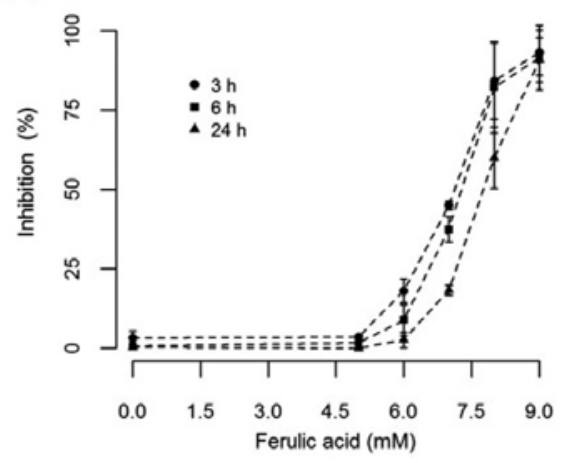

Figure 2. Effects of (a) gallic acid (GA) and (b) ferulic acid (FA) on hyphae inhibition at 3,6, and $24 \mathrm{hr}$ of treatment. SC5314 C. albicans cells were treated with GA or FA at different concentrations. Each point and vertical bar represents the mean \pm standard deviation of three replicates.

at a treatment duration of $3 \mathrm{hr}$ indicating that the GA activity reduces with time. The response of the $6 \mathrm{hr}$ treated sample was not significantly different from that of the $24 \mathrm{hr}$ sample $(p>0.05)$ with the exception of the highest level $(80 \mathrm{mM})$. At this concentration, the $24 \mathrm{hr}$ treatment percent inhibition was higher than at $6 \mathrm{hr}$. Considering that more yeast cells were present after $24 \mathrm{hr}$ of treatment compared with $6 \mathrm{hr}$, C. albicans hyphae may have remediated back to its yeast form as no proliferation occurs with this differentiation media, as stated previously, which was further supported by the lack of visual yeast buds as would be expected if proliferation was indeed occurring. To our knowledge, studies have not been reported on the GA suppression of the hyphae transition, but rather cell growth inhibition (Alves et al., 2014). Still, to ensure that the phenol was not a nutrient source for cell growth in this study, an experiment was conducted exposing yeast cells inoculated into the GlcNAc supplemented with the highest levels of phenols selected for this study. The results supported the previously cited study and showed that the number of yeast cells did not change significantly by $24 \mathrm{hr}$ when exposed to GA (data not shown).

FA significantly prevented hyphae formation in a concentrationdependent manner (Figure $2 \mathrm{~b}$ ) with $9 \mathrm{mM}$ producing a percent inhibition of $93.2 \pm 7.1 \%, 91.6 \pm 10.2 \%$, and $90.9 \pm 6.9 \%$ at 3,6 , and 24 $\mathrm{hr}$ of treatment, respectively. At 7 and $8 \mathrm{mM}$, the percent inhibition of FA ( $24 \mathrm{hr}$ ) was significantly lower compared with 3 and $6 \mathrm{hr}$ (Figure 2b) but was not different between any of the time points at $9 \mathrm{mM}$. 
FA was the most efficacious anticandidal as the $\mathrm{IC}_{50}$ at $24 \mathrm{hr}$ was 8.0 $\pm 0.09 \mathrm{mM}$ compared with $83.9 \pm 5.32 \mathrm{mM}$ obtained by GA (data not shown). The activity of FA against multiple types of fungi have been well documented (Guzman, 2014). Yet, only a few studies have reported on this abundant cinnamic acid ability to protect against $C$. albicans, and those studies only targeted growth suppression. In one study, a minimum inhibitory concentration (MIC) value of $659 \mu \mathrm{M}$ FA (Ergün, Çoban, Onurdag, \& Banoglu, 2011) prevented C. albicans growth, whereas another report showed a MIC value greater than 10 mM (Nakauchi, Ikemoto, Yamanishi, \& Ozaki, 2002). This difference in the inhibitory concentrations of the active molecule could be due to the different strains or media used.

\subsection{Effects of two phenols on C. albicans yeast-to-hyphae transition}

Two-three phenolics were then analyzed as potential synergistic inhibitors that specifically targets the $C$. albicans yeast-to-hyphae transition. Although the 3 and $6 \mathrm{hr}$ treatment periods were evaluated (data not shown), the effect of the combined phenols over $24 \mathrm{hr}$ was the primary focus of this study due to the community morphology during this time period. FA served as the base compound considering it was the most efficacious phenolic agent. Therefore, $F A(1,2,3$, and $4 \mathrm{mM})$ were each combined with GA at 5, 7.5, and $10 \mathrm{mM}$ and then studied for their ability to suppress the hyphae form. These concentrations were selected as they did not show any or only minimal protection as isolated components (Figure 2a,b). When treated with 4 mM FA, hyphae was readily apparent (Figure 3a). However, addition of GA at 5, 7.5, and $10 \mathrm{mM}$ to $4 \mathrm{mM}$ FA significantly inhibited hyphae resulting in $40.2 \pm 10.5,75.7 \pm 9.9$, and $75.3 \pm 10.3 \%$ suppression, respectively (Figure 3a). Although the $\mathrm{IC}_{50}$ for FA was $8.0 \pm 0.09 \mathrm{mM}$ and $\mathrm{GA}$ was $83.9 \pm 5.32 \mathrm{mM}$ at $24 \mathrm{hr}$, a 1.9-fold, 2.3-fold, and 2.6-fold reduction in the $\mathrm{IC}_{50}$ of FA occurred when combined with $5 \mathrm{mM}, 7.5 \mathrm{mM}$, and 10 $\mathrm{mM}$ GA, respectively (Figure $3 \mathrm{~b}$ ).

Isobolograms were configured to evaluate the interaction between FA and GA. As confirmed by the concave dashed line (Figure 3b) generated by plotting the $\mathrm{IC}_{50}$ for the phenols at each concentration tested, the compounds acted synergistically to inhibit hyphae formation. Additionally, the $\mathrm{Cl}$ was less than $1 ; \mathrm{Cl}=0.6$ for 5 

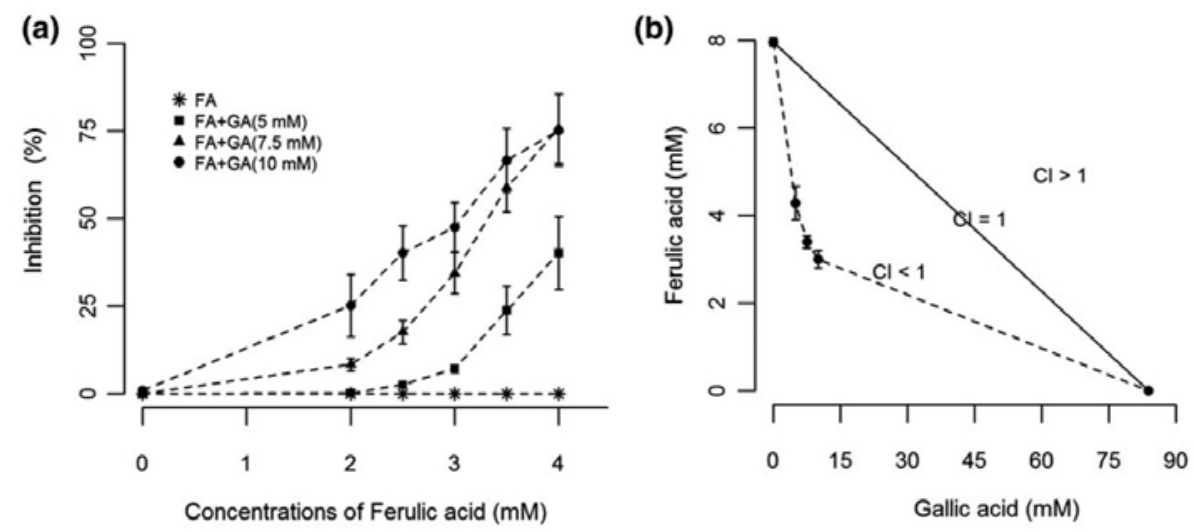

Figure 3. (a) Combined effects of gallic acid (GA) and FA on hyphae inhibition after $24 \mathrm{hr}$ treatment and (B) isobologram analysis. SC5314 Candida albicans cells were treated with $\mathrm{GA}$ combined with FA at different concentrations. According to the $I C_{50}$ determination, when $\mathrm{GA}(5,7.5$, and $10 \mathrm{mM})$ was combined with FA (4.3, 3.4 , and $3 \mathrm{mM}$, respectively), the combination index $(\mathrm{Cl})$ of each combination was less than 1 . Each point and vertical bar represents the mean \pm standard deviation of three replicates.

$\mathrm{mM} \mathrm{GA}+4.3 \mathrm{mM} \mathrm{FA}$; and $\mathrm{Cl}=0.5$ for combinations of $7.5 \mathrm{mM} \mathrm{GA}$ + 3.4 mM FA and $10 \mathrm{mM} \mathrm{GA}+3.0 \mathrm{mM}$ FA (Figure 3b). The dramatic decrease in the $\mathrm{IC}_{50}$ of $\mathrm{GA}(83.9 \pm 5.32 \mathrm{mM})$ and $\mathrm{FA}(8.0 \pm 0.09 \mathrm{mM})$ further confirm that these two compounds act as synergist inhibitors of the C. albicans switch.

\subsection{Effects of three phenols on C. albicans yeast-to-hyphae transition}

SA was added to the GlcNAc DM to determine whether a third compound could affect the $I C_{50}$ of GA and FA to produce a more potent synergistic effect. For these experiments, the same levels of FA:SA were used to simplify the isobolograms construction, whereas GA was added at 2.5, 7.5, and $25 \mathrm{mM}$. (The range of GA concentrations was increased to obtain a wider distribution of the points for the isobologram). Flasks containing only FA:SA at all concentrations tested and only GA at three fixed concentrations served as controls.

A significant improvement in protection occurred only after GA was added to the FA:SA combination. In the presence of $3 \mathrm{mM} F A$ : SA, hyphae was not inhibited (Figure 4a), but when GA was added at 2.5, 
(a)

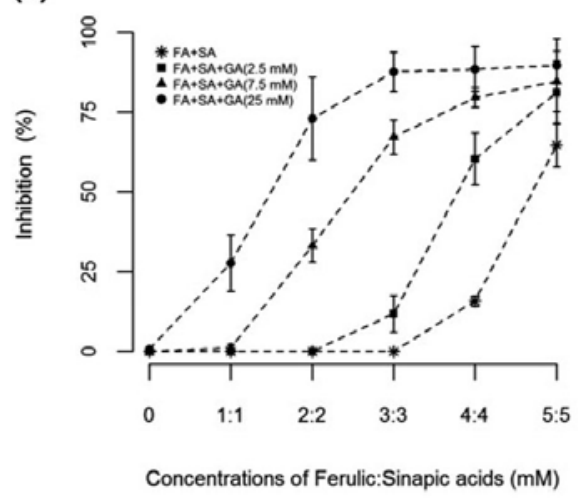

(b)

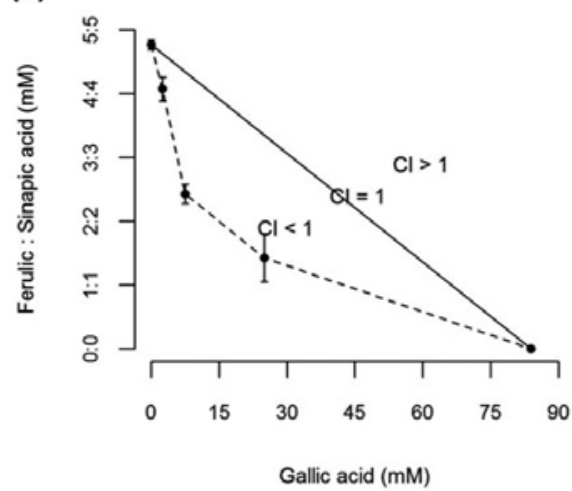

Figure 4. (a) Combined effects of gallic acid (GA), ferulic acid (FA), and sinapic acid (SA) on hyphae inhibition after $24 \mathrm{hr}$ treatment and (b) isobologram analysis. SC5314 Candida albicans cells were treated with GA combined with FA and SA at different concentrations. According to the $\mathrm{IC}_{50}$ determination, when $\mathrm{GA}(2.5,7.5$, and $25 \mathrm{mM})$ was combined with FA:SA $(4.1,2.4$, and $1.4 \mathrm{mM}$, respectively), the $\mathrm{Cl}$ of each combination was less than 1 . Each point and vertical bar represents the mean \pm standard deviation of three replicates.

7.5 , and $25 \mathrm{mM}$, inhibition increased to $11.8 \pm 5.82,67.2 \pm 5.28$, and $87.8 \pm 6.22 \%$, respectively. The isobologram showed that GA interacted synergistically with FA:SA as indicated by the concave line (Figure $4 \mathrm{~b}$ ) and confirmed by $\mathrm{Cl}$ for each data points, which was less than $1 ; \mathrm{Cl}=0.9$ for combination of $2.5 \mathrm{mM} \mathrm{GA}+4.1 \mathrm{mM} \mathrm{FA}: \mathrm{SA}$; and $\mathrm{Cl}=$ 0.6 for combination of $7.5 \mathrm{mM} \mathrm{GA}+2.4 \mathrm{mM}$ FA:SA and $25 \mathrm{mM} \mathrm{GA}+$ $1.4 \mathrm{mM}$ FA:SA. SA has been studied for its antimicrobial activity, but reports on its antifungal effect remain limited (Guzman, 2014). Nonetheless, the results show that this compound may be of interest for targeting a virulence factor or $C$. albicans research as the final I $C_{50}$ was $7.5 \mathrm{mM} \mathrm{GA}+2.4 \mathrm{mM}$ FA:SA.

During the course of this study, we recognized that $\mathrm{pH}$ may have affected percent inhibition value considering the wide concentration range of acidic compounds used. A study was thus conducted, where $\mathrm{pH}$ was adjusted in the DM to 4.5, 4.4, and 3.1, which simulated the conditions produced by $9 \mathrm{mM}$ FA, $5 \mathrm{mM}$ FA:SA, and $80 \mathrm{mM} \mathrm{GA}$, respectively. The yeast-to-hyphae transition was not inhibited by the lower $\mathrm{pH}$ indicating that the protective responses were due to other properties exerted by the phenolic compounds. 


\subsection{H3K56 acetylation in phenolic treated and nontreated C. albicans cells}

Genetic studies have been conducted on C. albicans, revealing potential new targets for antifungal therapy (Becker et al., 2010; da et al., 2010; Mishra, Baum, \& Carbon, 2011; Wurtele et al., 2010). In particular, Wurtele et al. (2010) detected that preserving the expression of the enzyme HST3 (histone deacetylase that removes H3K56ac genomewide) reduced $\mathrm{H} 3 \mathrm{~K} 56 \mathrm{ac}$ compared with cells with lower expression of this enzyme, resulting in cells with the hyphae phenotype. da et al. (2010) reported that H3K56ac was lost in mutants lacking the histone acetyltransferase responsible for H3K56ac (Rtt109) and a large proportion of cells were filamentous compared with wild-type yeast cells. Moreover, elevated expression was detected in the hyphal-induced gene (orf19.7531) located in the mutant cells ( $\mathrm{rtt109}^{-/-}$). Both studies used the same $C$. albicans strain used in the present work. Due to association between H3K56ac and morphogenesis of $C$. albicans, particularly the total absence of acetylation originating filamentation, we hypothesized that $\mathrm{H} 3 \mathrm{~K} 56 \mathrm{ac}$ may play an important role in the yeastto-hyphae transition. An experiment was therefore completed on $C$. albicans acetylation throughout its transition period, which is the first reported to our knowledge. We further monitored the H3K56ac profile of phenolic treated vs. its nontreated counterpart to determine if a correlation existed between acetylation and yeast to hyphae transition in response to a phenol treatment, thus being a possible target.

Histones were extracted at $0,3,6$, and $24 \mathrm{hr}$ from nontreated cells and from the $24 \mathrm{hr}$ treated cells using $7.5 \mathrm{mM} \mathrm{GA}+2.4 \mathrm{mM}$ FA:SA treatment. This treatment was used because the lowest concentrations of all three phenols were used among the three $\mathrm{IC}_{50}{ }^{\text {'s }}$ shown in Figure $4 \mathrm{~b}$. Immunoblot analysis of the protein extract detected H3K56ac in all samples (Figure 5a). Using densitometry, the gel was quantified (Figure $5 b$ ) by the relative density of each H3K56ac sample normalized to the $\mathrm{H} 3$ (loading control). H3K56ac was significantly higher in yeast cells $(0 \mathrm{hr})$ compared with hyphae cells at 3,6 , and $24 \mathrm{~h}$, although acetylation of samples was not significantly different between these three time points. These results suggest that $C$. albicans cells' histone $\mathrm{H} 3$ protein was deacetylated when induced to hyphae. Interestingly, the deacetylation results were significantly similar whether the cells were in a free germ form state ( $3 \mathrm{hr}$ ) or as clumping 
(a)

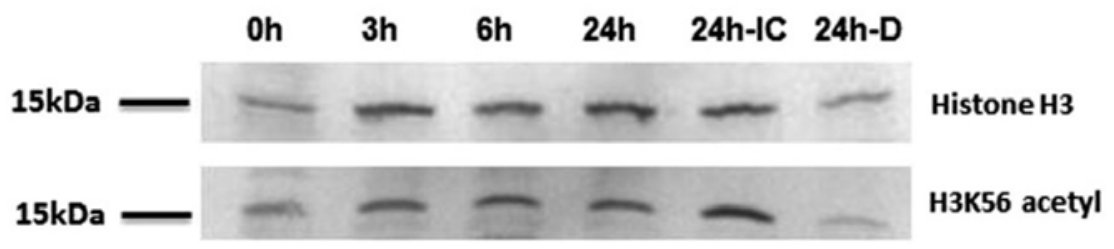

(b)

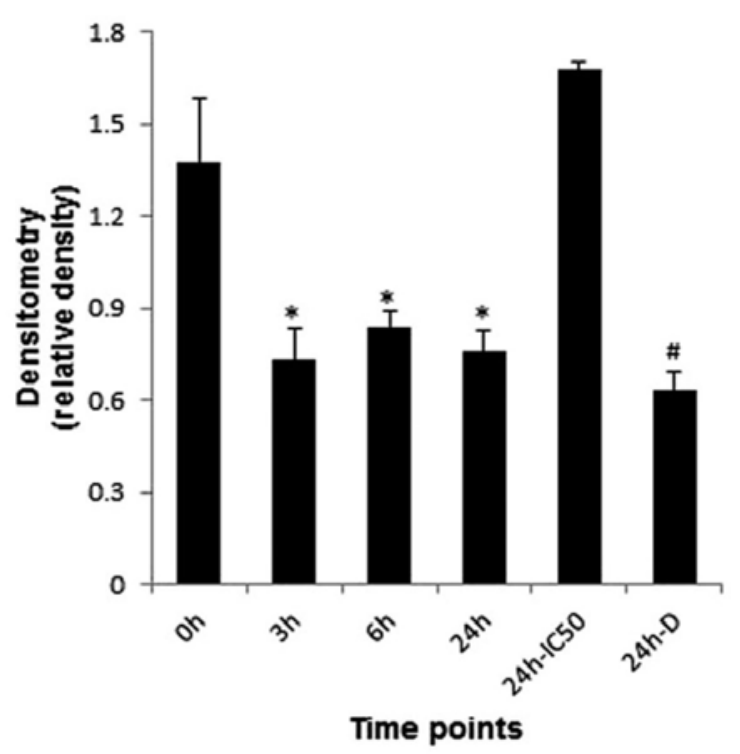

Figure 5. (a) Immunoblot of H3K56ac and total $\mathrm{H} 3$ in histone extracts from SC5314 strain during yeast-to-hyphae transition induced by $\mathrm{N}$-acetylglucosamine differentiation media at $37^{\circ} \mathrm{C}$. Non-treated samples ( $\left.0-24 \mathrm{~h}\right)$ were incubated in flasks containing only differentiation media, whereas treated samples $(24 \mathrm{hr}-\mathrm{IC})$ were incubated in differentiation media supplemented with $7.5 \mathrm{mM} \mathrm{GA}+2.4 \mathrm{mM}$ FA:SA $\left(I C_{50}\right)$. Cells incubated for $24 \mathrm{hr}$ in the presence of DMSO (24 hr-D) were used as positive control for treated samples. (b) Data from immunoblot were quantified by densitometry and $\mathrm{H} 3 \mathrm{~K} 56 \mathrm{ac}$ was normalized by H3 densitometry. ${ }^{*} \mathrm{p}<0.05 \mathrm{vs}$. $0 \mathrm{hr}$, $\# \mathrm{p}<0.05$ vs. $24 \mathrm{hr}-\mathrm{IC} \mathrm{C}_{50}$

growing hyphae ( 6 and $24 \mathrm{hr}$ ) indicating that deacetylation is involved throughout the transition or is an initiator that does not change once the process begins. Nonetheless, cells treated with GA + FA:SA levels required to inhibit $50 \%$ of hyphal growth resulted in $\mathrm{H} 3 \mathrm{~K} 56 \mathrm{ac}$ profile similar to yeast cells $(p>0.05)$. The phenols may, in part, prevent histone $\mathrm{H} 3$ deacetylation, maintaining the yeast $\mathrm{H} 3 \mathrm{~K} 56 \mathrm{ac}$ profile, which may be responsible for lower expression of a hyphae-induced gene (da Rosa et al., 2010). 


\section{Conclusion}

Phenols (GA and FA) tested in isolation exerted their activity against C. albicans yeast-to-hyphae transition at higher levels of the concentrations tested. When combined, however, both GA and FA levels decreased dramatically to achieve this antivirulence effect with even further reduction in concentration upon addition of SA. Importantly, the hyphal inhibitor effect of the GA-FA combination correlated to the maintenance of a histone $\mathrm{H} 3$ acetylation. Considering the conditions of incubation used (aerobic and deprivation of nutrients) and the high phenolic concentration needed for these studies, oral or topical treatments may be the more practical applications for this treatment approach. Nonetheless, this study is the first to substantiate that phenols are capable of acting as synergists to prevent $C$. albicans yeast-to-hyphae transition.

Acknowledgments - We are grateful to Subhashinee Wijeratne for Western Blot training and to Martônio Viana for crucial suggestions on this matter, and lastly, Kwame Andoh-Kumi for performing densitometry measurements (all from University of Nebraska-Lincoln).

Conflicts of interest - The authors declare no financial and commercial conflicts of interest.

\section{References}

Alves, C. T., Ferreira, I. C. F. R., Barros, L., Silva, S., Azeredo, J., \& Henriques, M. (2014). Antifungal activity of phenolic compounds identified in flowers from North Eastern Portugal against Candida species. Future Microbiology, 9(2), 139146. https://doi.org/10.2217/fmb.13.147

Becker, J. M., Kauffman, S. J., Hauser, M., Huang, L., Lin, M., Sillaots, S., ... Roemer, T. (2010). Pathway analysis of Candida albicans survival and virulence determinants in a murine infection model. Proceedings of the National Academy of Sciences, 107(51), 22044-22049. https://doi.org/10.1073/ pnas.1009845107

Bradford, M. M. (1976). A rapid and sensitive method for the quantitation of microgram quantities of protein utilizing the principle of proteindye binding. Analytical Biochemistry, 72, 248-254. https://doi. org/10.1016/0003-2697(76)90527-3 
Brown, A. J., \& Gow, N. A. (1999). Regulatory networks controlling Candida albicans morphogenesis. Trends in Microbiology, 7(8), 333-338. https://doi. org/10.1016/S0966-842X(99)01556-5

Canonico, B., Candiracci, M., Citterio, B., Curci, R., Squarzoni, S., Mazzoni, A., ... Piatti, E. (2014). Honey flavonoids inhibit Candida albicans morphogenesis by affecting DNA behavior and mitochondrial function. Future Microbiology, 9(4), 445-456. https://doi.org/10.2217/fmb.14.17

CDC. Centers for Disease Control and Prevention. 2013. Antibiotic resistance threats in the United States, 2013. Retrieved from CDC website: https://www. cdc.gov/drugresistance/pdf/ar-threats-2013-508.pdf

da Rosa, J. L., Boyartchuk, V. L., Zhu, L. J., \& Kaufman, P. D. (2010). Histone acetyltransferase Rtt109 is required for Candida albicans pathogenesis. Proceedings of the National Academy of Sciences of the United States of America, 107(4), 1594-1599.

Ergün, B. Ç., Çoban, T., Onurdag, F. K., \& Banoglu, E. (2011). Synthesis, antioxidant and antimicrobial evaluation of simple aromatic esters of ferulic acid. Archives of Pharmacal Research, 34(8), 1251-1261. https://doi.org/10.1007/ s12272-011-0803-y

Faria, N. C. G., Kim, J. H., Gonçalves, L. A. P., Martins, M. D. L., Chan, K. L., \& Campbell, B. C. (2011). Enhanced activity of antifungal drugs using natural phenolics against yeast strains of Candida and Cryptococcus. Letters in Applied Microbiology, 52(5), 506-513. https://doi.org/10.1111/j.1472-765X.2011.03032.x

Gallucci, M. N., Carezzano, M. E., Oliva, M. M., Demo, M. S., Pizzolitto, R. P., Zunino, M. P., ... Dambolena, J. S. (2014). In vitro activity of natural phenolic compounds against fluconazole-resistant Candida species: A quantitative structure-activity relationship analysis. Journal of Applied Microbiology, 116(4), 795-804. https:// doi.org/10.1111/jam.12432

Guzman, J. (2014). Natural Cinnamic acids, synthetic derivatives and hybrids with antimicrobial activity. Molecules, 19(12), 19292-19349. https://doi.org/10.3390/ molecules 191219292

Hasim, S., Tati, S., Madayiputhiya, N., Nandakumar, R., \& Nickerson, K. W. (2013). Histone biotinylation in Candida albicans. FEMS Yeast Research, 13(6), 529-539. https://doi.org/10.1111/1567-1364.12056

Hornby, J. M., Jensen, E. C., Lisec, A. D., Tasto, J. J., Jahnke, B., Shoemaker, R., ... Nickerson, K. W. (2001). Quorum sensing in the dimorphic fungus Candida albicans is mediated by farnesol. Applied and Environmental Microbiology, 67(7), 2982-2992. https://doi.org/10.1128/AEM.67.7.2982-2992.2001

Huang, G., Yi, S., Sahni, N., Daniels, K. J., Srikantha, T., \& Soll, D. R. (2010). $\mathrm{N}$-acetylglucosamine induces white to opaque switching, a mating prerequisite in Candida albicans. PLoS Pathogens, 6(3), e1000806. https://doi.org/10.1371/ journal.ppat.1000806

Junio, H. A., Sy-Cordero, A. A., Ettefagh, K. A., et al. (2011). Synergy-directed fractionation of botanical medicines: A case study with goldenseal (Hydrastis canadensis). Journal of Natural Products, 74(7), 1621-1629. 
Kanwal, Q., Hussain, I., Latif Siddiqui, H., \& Javaid, A. (2010). Antifungal activity of flavonoids isolated from mango (Mangifera indica L.) leaves. Natural Product Research, 24(20), 1907-1914. https://doi.org/10.1080/14786419.2010.488628

Kaplan, T., Liu, C. L., Erkmann, J. A., Holik, J., Grunstein, M., Kaufman, P. D., ... Rando, O. J. (2008). Cell cycle-and chaperone-mediated regulation of H3K56ac incorporation in yeast. PLoS Genetics, 4(11), e1000270. https://doi.org/10.1371/ journal.pgen.1000270

Kazuko, O. S., Sato, Y., \& Azuma, T. (2010). Resveratrol impaired the morphological transition of Candida albicans under various hyphae-inducing conditions. Journal of Microbiology and Biotechnology, 20(5), 942-945.

Kullberg, B. J., \& Arendrup, M. C. (2015). Invasive Candidiasis. N Engl J Ed, 373, 1445-1456. https://doi.org/10.1056/NEJMra1315399

Lewis, R. E., \& Kontoyiannis, D. P. (2001). Rationale for combination antifungal therapy. Pharmacotherapy, 21, 149s-164s. https://doi.org/10.1592/ phco.21.12.149S.34505

Li, Z., Wu, C., Wu, J., et al. (2014). Synergistic antitumor effects of combined deguelin and cisplatin treatment in gastric cancer cells. Oncology Letters, 1, 1603-1607.

Lortholary, O., Desnos-Ollivier, M., Sitbon, K., Fontanet, A., Bretagne, S., \& Dromer, F. (2011). Recent exposure to caspofungin or fluconazole influences the epidemiology of candidemia: A prospective multicenter study involving 2,441 patients. Antimicrobial Agents and Chemotherapy, 55, 532-538. https://doi. org/10.1128/AAC.01128-10

Magill, S. S., Edwards, J. R., Bamberg, W., Beldavs, Z. G., Dumyati, G., Kainer, M. A., ... Emerging Infections Program Healthcare-Associated Infections and Antimicrobial Use Prevalence Survey Team (2014). Multistate point-prevalence survey of health care-associated infections. The New England Journal of Medicine, 370(13), 1198-1208. https://doi.org/10.1056/NEJMoa1306801

Manach, C., Scalbert, A., Morand, C., Rémésy, C., \& Jiménez, L. (2004). Polyphenols: Food sources and bioavailability. The American Journal of Clinical Nutrition, 79(5), 727-747. https://doi.org/10.1093/ajcn/79.5.727

Miceli, M. H., Díaz, J. A., \& Lee, S. A. (2011). Emerging opportunistic yeast infections. The Lancet Infectious Diseases, 11(2), 142-151. https://doi. org/10.1016/S1473-3099(10)70218-8

Mishra, P. K., Baum, M., \& Carbon, J. (2011). DNA methylation regulates phenotype-dependent transcriptional activity in Candida albicans. Proceedings of the National Academy of Sciences of the United States of America, 108(29), 11965-11970. https://doi.org/10.1073/pnas.1109631108

Mosel, D. D., Dumitru, R., Hornby, J. M., Atkin, A. L., \& Nickerson, K. W. (2005). Farnesol concentrations required to block germ tube formation in Candida albicans in the presence and absence of serum. Applied and Environmental Microbiology, 71(8), 4938-4940. https://doi.org/10.1128/ AEM.71.8.4938-4940.2005 
Nakauchi, M., Ikemoto, S., Yamanishi, H., \& Ozaki, Y. (2002). Antimicrobial activities of synthetic ferulic acid derivatives. Food Preserv Sci, 28, 183-188. https://doi. org/10.5891/jafps.28.183

Phan, Q. T., Myers, C. L., Fu, Y., et al. (2007). Als3 is a Candida albicans invasin that binds to cadherins and induces endocytosis by host cells. PLoS Biology, 5(3), 0543-0557. https://doi.org/10.1371/journal.pbio.0050064

Saito, H., Tamura, M., Imai, K., Ishigami, T., \& Ochiai, K. (2013). Catechin inhibits Candida albicans dimorphism by disrupting Cek1 phosphorylation and cAMP synthesis. Microbial Pathogenesis, 56, 16-20. https://doi.org/10.1016/j. micpath.2013.01.002

Sardi, J. C. O., Almeida, A. M. F., \& Mendes Giannini, M. J. S. (2011). New antimicrobial therapies used against fungi present in subgingival sites-a brief review. Archives of Oral Biology, 56(10), 951-959. https://doi.org/10.1016/j. archoralbio.2011.03.007

Shareck, J., \& Belhumeur, P. (2011). Modulation of morphogenesis in Candida albicans by various small molecules. Eukaryotic Cell, 10(8), 1004-1012. https:// doi.org/10.1128/EC.05030-11

Singh, P., Ghosh, S., \& Datta, A. (2001). Attenuation of virulence and changes in morphology in Candida albicans by disruption of the $\mathrm{N}$-acetylglucosamine catabolic pathway. Infection and Immunity, 69(12), 7898-7903. https://doi. org/10.1128/IAl.69.12.7898-7903.2001

Sudbery, P., Gow, N., \& Berman, J. (2004). The distinct morphogenic states of Candida albicans. Trends in Microbiology, 12(7), 317-324. https://doi. org/10.1016/j.tim.2004.05.008

Wurtele, H., Tsao, S., Lépine, G., Mullick, A., Tremblay, J., Drogaris, P., ... Raymond, M. (2010). Modulation of histone H3 lysine 56 acetylation as an antifungal therapeutic strategy. Nature Medicine, 16(7), 774-778. https://doi.org/10.1038/ $\underline{n m .2175}$

Zida, A., Bamba, S., Yacouba, A., Ouedraogo-Traore, R., \& Guiguemdé, R. T. (2017). Anti-Candida albicans natural products, sources of new antifungal drugs: $\mathrm{A}$ review. J Mycol Med, 27(1), 1-19. https://doi.org/10.1016/j.mycmed.2016.10.002

Citation: Câmara CRS, Shi Q, Pedersen M, Zbasnik R, Nickerson KW, Schlegel V. Histone acetylation increases in response to ferulic, gallic, and sinapic acids acting synergistically in vitro to inhibit Candida albicans yeast-to-hyphae transition. Phytotherapy Research. 2019;33:319-326. https://doi.org/10.1002/ptr.6222 